\title{
OPEN 3D X-ray tomographic analysis reveals how coesite is preserved in Muong Nong-type tektites
}

\author{
Matteo Masotta ${ }^{1,2}$, Stefano Peres ${ }^{1,3}$, Luigi Folco ${ }^{1,2}{ }^{1,2}$, Lucia Mancini ${ }^{4,5}$, Pierre Rochette ${ }^{6}$, \\ Billy P. Glass ${ }^{7}$, Fabrizio Campanale ${ }^{1,2,8}$, Nicolas Gueninchault ${ }^{9}$, Francesco Radica $^{10}$, \\ Sounthone Singsoupho ${ }^{11}$ \& Enrique Navarro ${ }^{12}$
}

Muong Nong-type (MN) tektites are a layered type of tektite associated to the Australasian strewn field, the youngest ( $790 \mathrm{kyr}$ ) and largest on Earth. In some $\mathrm{MN}$ tektites, coesite is observed in association with relict quartz and silica glass within inclusions surrounded by a froth layer. The formation of coesite-bearing frothy inclusions is here investigated through a 3D textural multiscale analysis of the vesicles contained in a MN tektite sample, combined with compositional and spectroscopic data. The vesicle size distribution testifies to a post-shock decompression that induced melting and extensive vesiculation in the tektite melt. Compared to free vesicles, nucleated homogeneously in the tektite melt, froth vesicles nucleated heterogeneously on relict quartz surfaces at the margins of coesite-bearing inclusions. The rapid detachment of the froth vesicles and prompt reactivation of the nucleation site favoured the packing of vesicles and the formation of the froth structure. Vesicle relaxation time scales suggest that the vesiculation process lasted few seconds. The formation of the froth layer was instrumental for the preservation of coesite, promoting quenching of the inclusion core through the subtraction of heat during froth expansion, thereby physically insulating the inclusion until the final quench of the tektite melt.

Coesite is a high-pressure polymorph of $\mathrm{SiO}_{2}$ and a diagnostic feature of shock metamorphism associated with impact cratering on quartz-bearing target rocks ${ }^{1}$. The preservation of coesite as a metastable phase in shocked rocks that experienced peak pressures and temperatures much beyond its stability field (i.e., pressures of 3-10 $\mathrm{GPa}$ and temperatures below $2700^{\circ} \mathrm{C}$ ) represents a controversial issue ${ }^{2}$. For this reason, different mechanisms of coesite formation have been proposed, including coesite crystallization from an impact silica melt during shock unloading ${ }^{3-5}$, subsolidus nucleation from highly densified diaplectic silica glass ${ }^{6}$ and direct subsolidus quartz-coesite transition upon shockwave reverberation ${ }^{2,7}$. Regardless of the formation mechanism, the kinetic of the coesite $\rightarrow$ quartz transformation determines the possibility of coesite survival in a transient high-pressure and high-temperature regime (e.g. ${ }^{8}$ ). Hence, in order to explain the survival of coesite in impact rocks, a combined examination of the textural features and of the physical conditions of the shock is required.

In the Australasian tektite strewn field, coesite was found as microcrystalline grains in partly melted mineral inclusions within impact melt glasses (namely tektites ${ }^{9,10}$ ) and in shocked ejecta found in the Australasian microtektite layer ${ }^{7,11}$. Muong Nong (MN) tektites constitute one of the three tektite types associated with the Australasian strewn field and the only one where coesite was occasionally found ${ }^{9,10}$. Compared to splashform and ablated types, MN tektites typically occur as small fragments (with the exception of a few very large samples, weighting some tens of $\mathrm{kg}$ ) with no signs of ablation. They are characterized by a heterogeneous chemical composition and exhibit a characteristic layering, for which they are also known as layered tektites ${ }^{12}$. Moreover, they display a

\footnotetext{
${ }^{1}$ Dipartimento di Scienze della Terra, Università di Pisa, Pisa, Italy. ${ }^{2}$ CISUP, Centro per I'Integrazione della Strumentazione dell'Università di Pisa, Pisa, Italy. ${ }^{3}$ Department of Lithospheric Research, University of Vienna, Wien, Austria. ${ }^{4}$ Elettra-Sincrotrone Trieste SCpA, Basovizza, Trieste, Italy. ${ }^{5}$ LINXS-Lund Institute for Advanced Neutron and X-Ray Science, Lund, Sweden. ${ }^{6}$ CEREGE, Aix-Marseille University, CNRS, INRA, IRD, Aix-en-Provence, France. ${ }^{7}$ Department of Earth Sciences, University of Delaware, Newark, DE, USA. ${ }^{8}$ Center for Nanotechnology Innovation@NEST, Istituto Italiano di Tecnologia (IIT), Pisa, Italy. ${ }^{9}$ Zeiss Research Microscopy Solutions, Carl Zeiss SAS, Marly-le-Roi, France. ${ }^{10}$ Dipartimento di Scienze, Università degli Studi Roma Tre, Roma, Italy. ${ }^{11}$ Department of Physics, Faculty of Natural Sciences, National University of Laos, Vientiane, Laos. ${ }^{12}$ Instituto di Geologia y Geofisica CIGEO, Universidad Nacional Autónoma de Nicaragua, Managua, Nicaragua. ${ }^{\bowtie}$ email: matteo.masotta@ unipi.it
} 
higher water content (up to $300 \mathrm{ppm}$ ) as compared to splashform tektites (up to $209 \mathrm{ppm}$ ) ${ }^{13,14}$ and microtektites collected in Antarctica $(<20-206 \mathrm{ppm})^{15}$ and a lower concentration of ${ }^{10} \mathrm{Be}$ as compared to ablated tektites from Australia $^{16}$ and microtektites from Antarctica ${ }^{17}$. These geochemical and isotopic data indicate a deeper origin in the target rock of MN tektites and a consequently lower ejection velocity, which suggests that they are closer to the source crater than tektites from the rest of the strewn field outside of Indochina ${ }^{18}$. An impact location in Indochina is actually consistent with the geographic distribution and other petrographic and geochemical trends in both tektites and microtektites ${ }^{19-24}$ and, recently, a gravity anomaly observed in Laos was proposed as geophysical evidence of a crater buried under younger volcanic rocks of the Bolaven volcanic field ${ }^{25}$.

A detailed petrographic and chemical investigation of the MN tektite examined in this study (sample MP26 from Muang Phin, Laos) has been presented by Glass et al. ${ }^{10}$. Characteristic features of sample MP26 are: i) the layering of the vesicle-bearing silicate melt with slightly variable composition, ii) the occurrence of inclusions constituted by silica glass (hereafter referred to as lechatelierite inclusions) and iii) the presence of white opaque inclusions constituted by a densely vesiculated (froth) layer of $\mathrm{SiO}_{2}$-rich melt enclosing a core composed by a mixture of coesite, relict quartz and silica glass (hereafter referred to as coesite-bearing frothy inclusions). Glass et al. ${ }^{10}$ proposed that the presence of the froth layer in the coesite-bearing inclusions was fundamental for the survival of the coesite, as it acted as a heat sink and physical barrier during the solidification of the tektite. Nonetheless, the mechanism of formation of such an uncommon petrographic feature and the source of the volatile phase responsible of the vesiculation of $\mathrm{MN}$ tektite remain unsolved. These are crucial factors in defining the physical conditions for the formation of MN tektites and, more specifically, in understanding the entire process of coesite formation and survival in impact melt rocks.

In order to address these problems, we investigated the mechanisms and time scales of vesicle formation, in the general frame of tektite formation process. For this purpose, we performed a multiscale, three-dimensional (3D) characterization of the vesicles contained in MP26 by combining laboratory-based and synchrotron radiation (SR) phase-contrast X-ray computed microtomography $(\mu \mathrm{CT})$ imaging techniques. Laboratory-based CT measurements have been performed using a custom-developed microfocus system (MCT) and a commercial 3D X-ray microscope (XRM). By integrating the 3D textural data with micro-chemical and spectroscopic data (Fourier-transform infrared spectroscopy, FTIR), we reconstructed the mechanisms of vesiculation and their time scales during the formation of the MN tektite, corroborating the hypothesis that the development of froth structures constitutes an effective process for the preservation of coesite and other key shock-metamorphic features in impact melt rocks.

\section{Results}

2D textural and chemical analysis. Optical microscope images of MP26 show a characteristic layering, made evident by the brown shades of the glassy bands and by the common orientation of larger $(>500 \mu \mathrm{m}$; referred to the length of the major axis), elongated vesicles (Fig. 1a). The distribution of the vesicles on a polished surface is rather inhomogeneous, with the higher concentration of vesicles observed in planes parallel to the layering of the tektite, corresponding to certain glassy bands and regardless of the colour (Fig. 1b). The chemical composition of the tektite glass is very similar to that of a volcanic glass (namely a rhyolite) or a dominantly quartz-feldspatic lithology (Table S1). The colour shades of the glass bands correspond to variable intensities in the backscattered electron (BSE) images and are related to small compositional heterogeneities of the tektite. Pale brown glassy bands appear darker in the BSE images and display a small enrichment in $\mathrm{SiO}_{2}$ (up to 5 wt.\% higher) as compared to the dark brown bands, which appear brighter in the BSE images as result of slightly higher $\mathrm{FeO}, \mathrm{MgO}$ and $\mathrm{CaO}$ contents (up to $1 \mathrm{wt} \%$ for each oxide). Within this variability, the major element composition is comparable with chemical data reported in literature ${ }^{10,18,26}$ for MN tektites (including MP26).

Observed at the microscale, the vesicles occur either as individual vesicles isolated within the tektite glass (free vesicles) or as compact vesicle aggregates in the froth surrounding the coesite-bearing frothy inclusions (froth vesicles). The free vesicles are normally larger than the froth vesicles and range in size from 10 to $2000 \mu \mathrm{m}$ (with the exception of a few very large vesicles with length of the major axis $>2000 \mu \mathrm{m}$ ). Their cross-sectional shape is mostly circular, although larger $(>500 \mu \mathrm{m})$ vesicles appear elliptical and with a preferential elongation parallel to the layering of the tektite. In contrast, the smaller $(5-50 \mu \mathrm{m})$ froth vesicles exhibit less spherical shapes and overall increase in size from the contact with the inclusion towards the tektite melt (Fig. 1c).

Inclusions are essentially of two types, coesite-bearing frothy inclusions (Fig. 1c-f) and lechatelierite inclusions (Fig. 1g,h). Coesite-bearing frothy inclusions are generally larger $(200-600 \mu \mathrm{m})$ and more abundant than lechatelierite ones $(100-300 \mu \mathrm{m})$. Glass et al. ${ }^{10}$ described the texture of these inclusions and reported a number of $\sim 14$ inclusions per $\mathrm{cm}^{-2}$. The core of the inclusions is generally characterized by silica glass, coexisting with microcrystalline $(<2 \mu \mathrm{m})$ aggregates of coesite and relict quartz grains, whilst towards the edge, the relict quartz grains are often arranged to form a rim that separates the core of the inclusion from the outer, up to $120 \mu \mathrm{m}$ thick, froth layer (Fig. 1e,f). In many inclusions, the relict quartz rim is discontinuous and exhibits gaps where the froth layer appears less developed and the inclusion core is in contact with the outer tektite melt (see Fig. 2 of Glass et al. ${ }^{10}$ ). Compared to coesite-bearing frothy inclusions, lechatelierite inclusions are characterized by silica glass and large $(>20 \mu \mathrm{m})$, convoluted vesicles (Fig. $1 \mathrm{~g}, \mathrm{~h})$. Small $(5-10 \mu \mathrm{m})$ and rare inclusions of Fe-Ni-S alloys have been also observed, but not further investigated $\left(\mathrm{cfr} .{ }^{27}\right.$ ). As already observed for the vesicles, a spatial relationship exists between the tektite layering and the shape and distribution of coesite-bearing frothy inclusions. Both the elongation and concentration of the inclusions increase in the layers containing the higher concentration of vesicles.

The $\mathrm{H}_{2} \mathrm{O}$ concentration in MP26, determined using FTIR spectroscopy along a transect perpendicular to the layering, ranges from a minimum of $166 \mathrm{ppm}$ to a maximum of $228 \mathrm{ppm}$, with an average value of $200 \pm 18 \mathrm{ppm}$ (Fig. 2). No correlation is observed between the $\mathrm{H}_{2} \mathrm{O}$ concentration and the colour/composition of the glass 


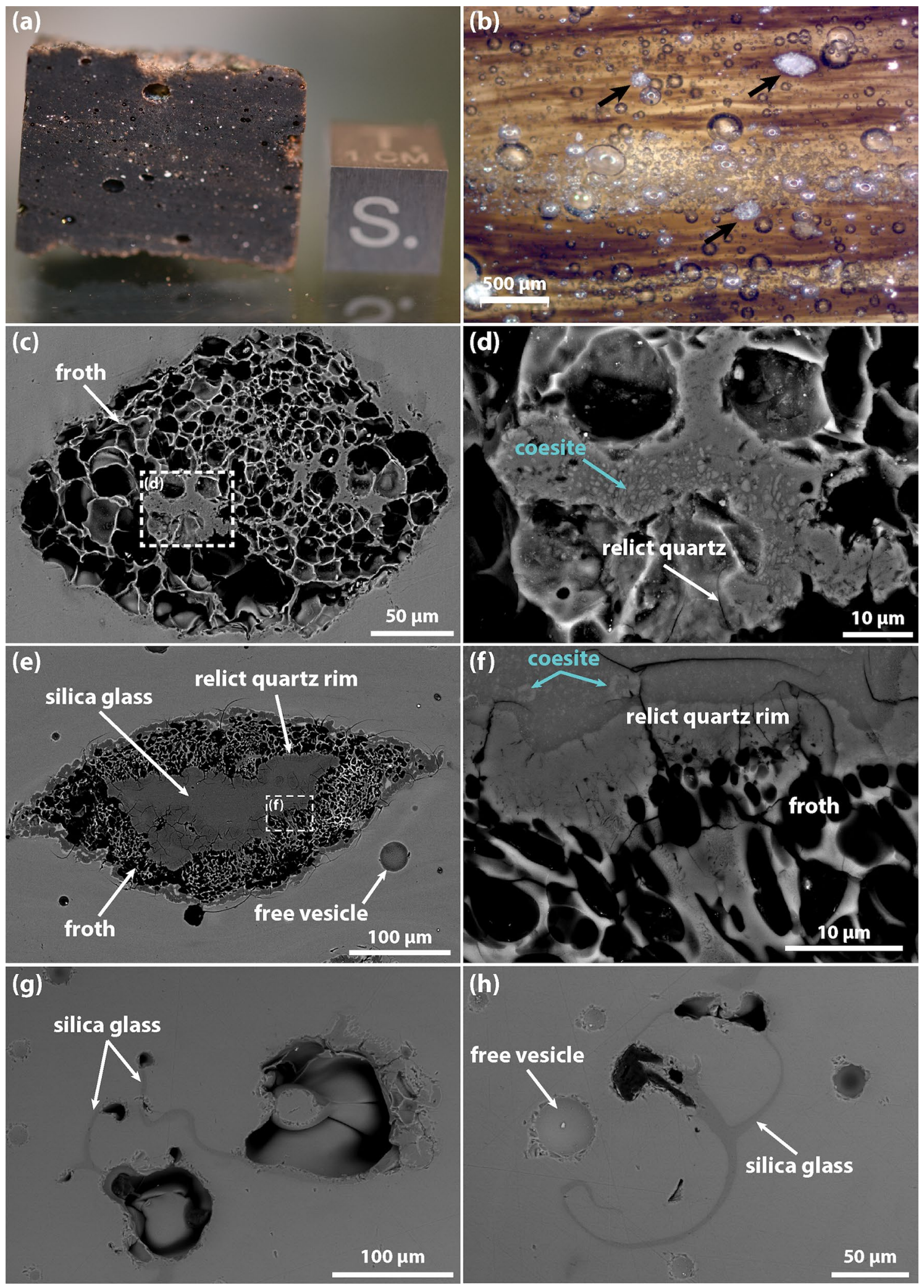

Figure 1. Sample MP26 (a) and optical microscope image of a thin slab of MP26, the location of frothy inclusions is indicated by the arrows (b). Backscattered electron images of a sub-spherical coesite-bearing inclusion, characterized by coesite microcrystals and relict quartz crystals (c,d). Backscattered electron images of an elongated coesite bearing inclusion (from Glass et al. ${ }^{10}$ ), characterized by a relict quartz rim and froth vesicles that are increasingly larger outward from the inclusion $(\mathbf{e}, \mathbf{f})$. Backscattered electron images of two lechatelierite inclusions (g,h). 


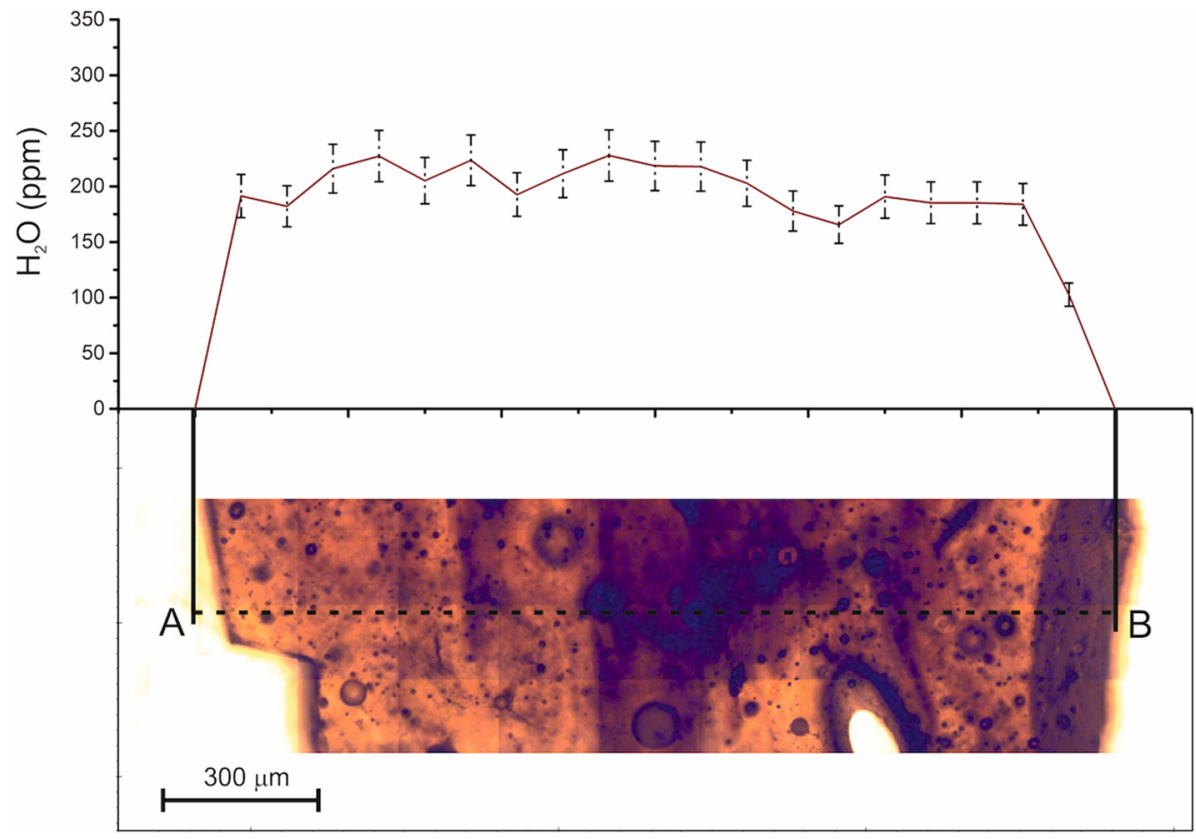

Figure 2. Fourier-transform infrared spectroscopy (FTIR) transect obtained on a $285 \mu \mathrm{m}$ slab of MP26 showing the intensity of $\mathrm{H}_{2} \mathrm{O}$ absorbance in the different bands. The error bars indicate the uncertainty in the $\mathrm{H}_{2} \mathrm{O}$ measurement in each point of the transect.

\begin{tabular}{|l|l|l|l|l|l|l|}
\hline Sample & Method & Isotropic voxel size $(\boldsymbol{\mu m})$ & Cut-off $(\boldsymbol{\mu m})$ & $\boldsymbol{V O I}\left(\mathbf{m m}^{3}\right)$ & $\Phi(\mathbf{v o l} . \%)$ & $V N D\left(\mathbf{m m}^{-3}\right)$ \\
\hline MP26a & XRM & 12.48 & 15 & 482 & 4.7 & $1.3 \times 10^{2}$ \\
\hline MP26a & XRM & 4.24 & 10 & 60 & 4.8 & $2.9 \times 10^{2}$ \\
\hline MP26a & XRM & 1.09 & 3 & 0.82 & 8.9 & $5.2 \times 10^{3}$ \\
\hline MP26a & MCT & 5.00 & 10 & 125 & 4.9 & $2.6 \times 10^{2}$ \\
\hline MP26b & SR- $\mu$ CT & 2.50 & 5 & 20.36 & 8.8 & $4.3 \times 10^{3}$ \\
\hline MP26b & SR- $\mu$ CT & 2.50 & 5 & 20.36 & 0.4 & 9.8 \\
\hline MP26c & SR- $\mu$ CT & 0.90 & 3 & 0.67 & 2.2 & $4.3 \times 10^{3}$ \\
\hline
\end{tabular}

Table 1. Summary of 3D textural analysis of VOIs extracted from XRM, MCT and SR- $\mu$ CT data on MP26. a Segmentation of coesite-bearing frothy inclusions in the same VOI used for MP26b (row above).

bands of the tektite. Our measurements are consistent with previous determinations of $\mathrm{H}_{2} \mathrm{O}$ content in $\mathrm{MN}$ tektites ${ }^{13}$ and confirm that MP26 is slightly enriched in $\mathrm{H}_{2} \mathrm{O}$ compared to other Australasian distal ejecta, such as splashform tektites and the microtektites found in the deep ocean sediments and in the transantarctic mountains $(<20-246 \mathrm{ppm})^{13,15}$.

3D morphology and distribution of vesicles and coesite-bearing frothy inclusions. A multiscale 3D textural analysis was performed on different volumes of interest (VOIs) by combining different X-ray $\mu \mathrm{CT}$ instruments, varying the voxel size from 12.48 to $0.90 \mu \mathrm{m}$ (Table 1). Due to the heterogeneity of MN tektite, a minimum representative elementary volume $(R E V)$ of $60 \mathrm{~mm}^{3}$ was determined. Consistent results of bulk vesicularity $(\phi)$ of 4.7-4.9 vol.\% are obtained only for VOIs larger than the $R E V$, whereas reliable vesicle number density (VND) values in the order of $10^{3}-10^{4} \mathrm{~mm}^{-3}$ are obtained only in the analysis of smaller VOIs at higher spatial resolution (allowing to detect and analyse vesicles with diameter as small as $3 \mu \mathrm{m}$ ).

As already observed by 2D microscopy analyses, the 3D morphology of the free vesicles ranges from nearly spherical to ellipsoidal, with the larger (length of the major axis $>200 \mu \mathrm{m}$ ) vesicles showing the higher deviation from the spherical shape and a common orientation parallel to the layering of the tektite (Fig. 3a; Video SV1). The 3D imaging characterization of the investigated VOIs reveals regions with different density of vesicles and inclusions that correspond to different layers of the tektite (Fig. 3b). The coesite-bearing frothy inclusions can be identified as individual objects, as they appear enclosed by the densely-packed froth vesicles, whose shapes range from spherical to tubular and belt-shaped (Fig. 3c; Fig. S4 and Video SV2).

The $3 \mathrm{D}$ analysis of textural parameters obtained from all the analytical datasets (XRM, MCT and SR- $\mu$ CT) consistently confirms the decrease of the sphericity with increasing size of both free and froth vesicles. Note that 


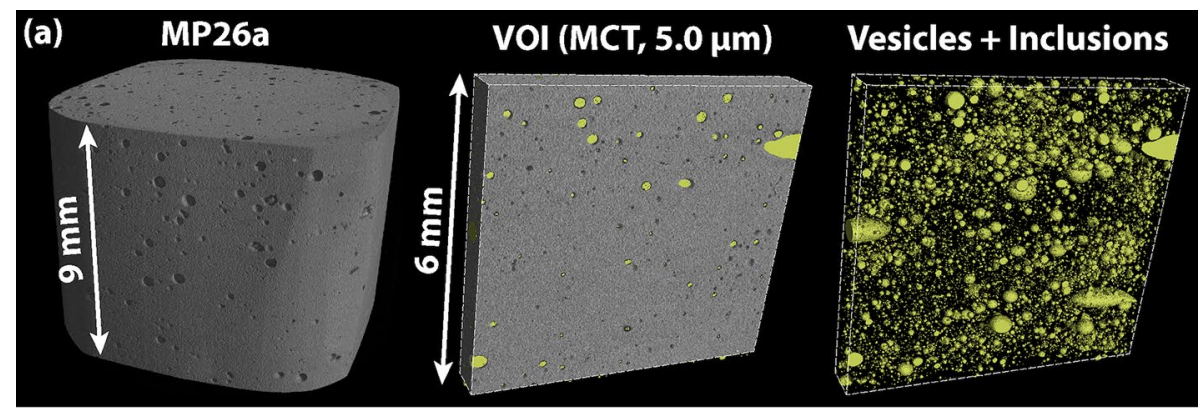

(b) VOI (SR- $\mu C T, 2.5 \mu \mathrm{m})$
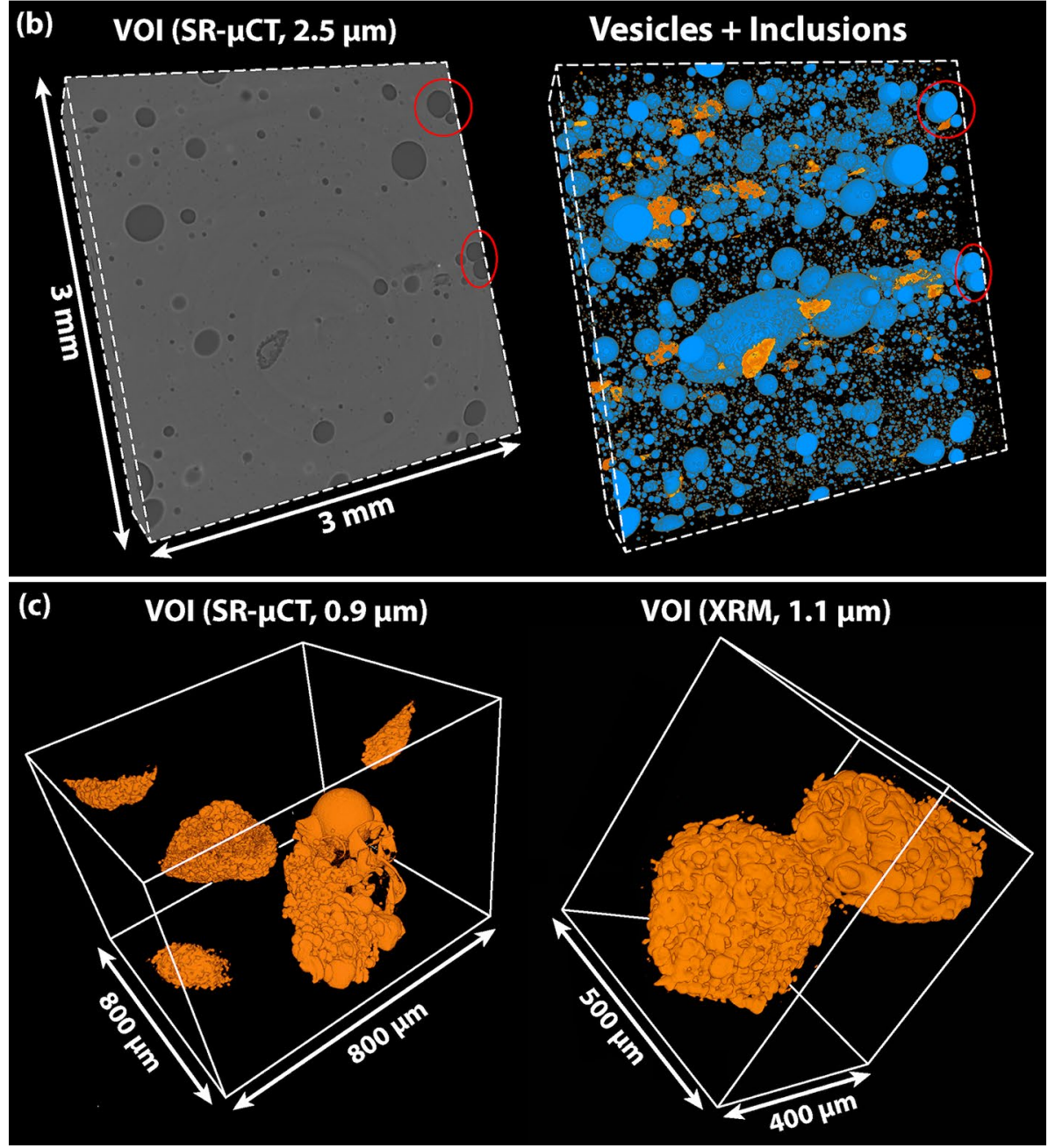

Figure 3. Volume rendering of MP26a obtained by MCT data reconstructed with an isotropic voxel size of $5.0 \mu \mathrm{m}$ and isosurface rendering after segmentation of all voids (a). Volume rendering of MP26b obtained using SR- $\mu$ CT data reconstructed with an isotropic voxel size of $2.5 \mu \mathrm{m}$ and isosurface rendering after segmentation of vesicles (coloured in blue) and inclusions (coloured in orange); red circles indicate free vesicles quenched before coalescence (b). Isosurface rendering of coesite-bearing frothy inclusions obtained using SR- $\mu \mathrm{CT}$ data reconstructed with an isotropic voxel size of $0.9 \mu \mathrm{m}$ and XRM data reconstructed with an isotropic voxel size of $1.09 \mu \mathrm{m}(\mathbf{c})$.

the two types of vesicles form two different trends in Fig. 4a, with froth vesicles having much lower sphericity than free vesicles, due to their irregular morphology (Fig. 3c). A similar trend is observed for coesite-bearing frothy inclusions, whose lower sphericity is due to the irregular shape of the core and enhanced by the presence of the froth layer (Fig. 4a; Fig. S4). The vesicle size distribution (VSD) curves for the vesicles display continuous trends of decreasing abundance with increasing size, with median values in the classes with equivalent sphere diameter of 10-15 $\mu \mathrm{m}$ (SR- $\mu$ CT data with isotropic voxel size of 0.90 and $2.50 \mu \mathrm{m}$ and XRM data with isotropic voxel size of $1.06 \mu \mathrm{m}$ ) and 15-20 $\mu \mathrm{m}$ (XRM and MCT data with isotropic voxel size of 12.48, 5.00 and $4.24 \mu \mathrm{m}$ ) (Fig. 4b). The difference in the median value is related to the different cut-off imposed by the voxel resolution. We note that the $3 \mathrm{D}$ textural analyses obtained at higher voxel resolution, although calculated on VOIs smaller 

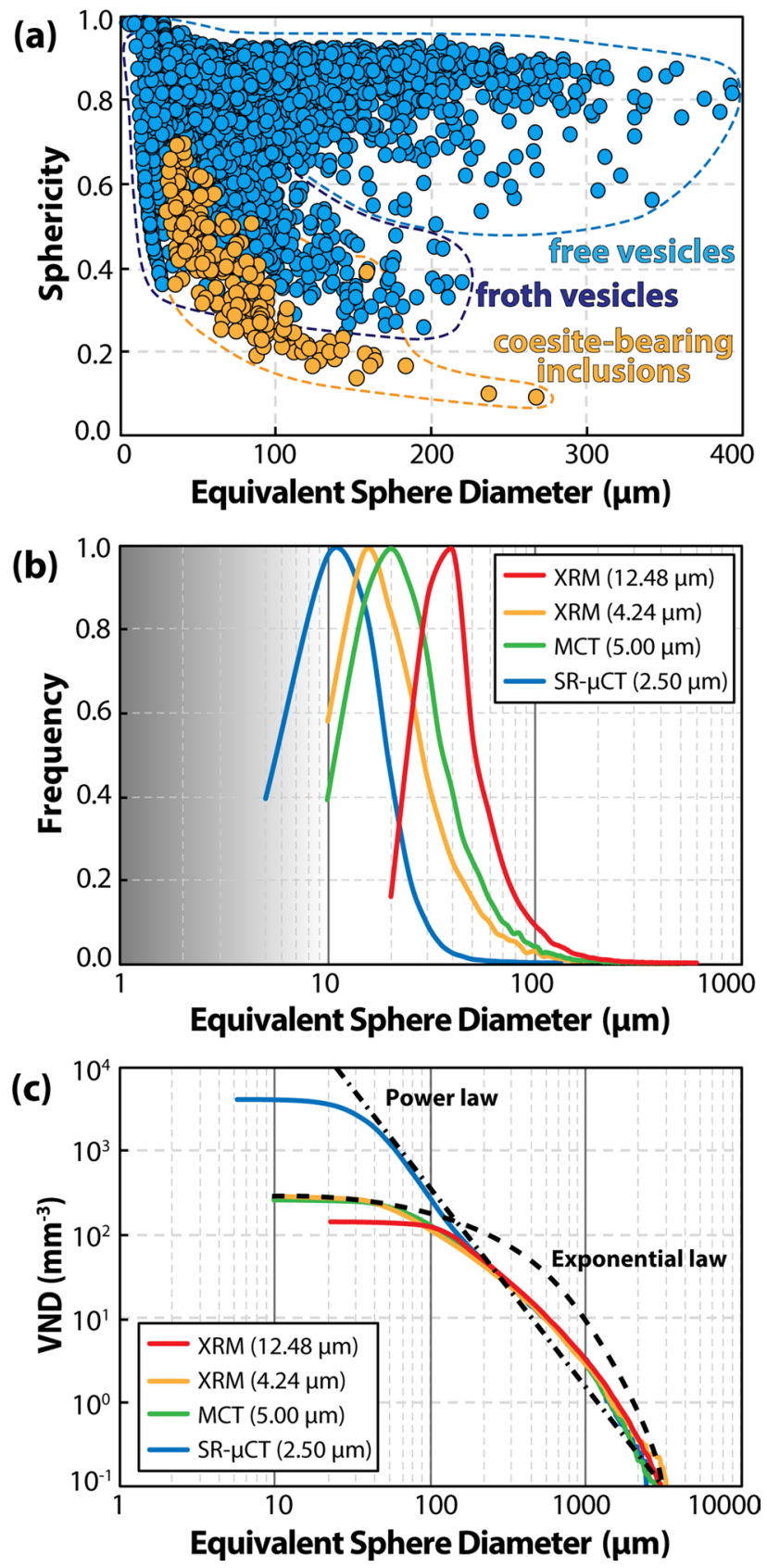

Figure 4. Results of 3D analysis of textural parameters for different volumes of MP26 analysed at different voxel resolutions. The sphericity of both free and froth vesicles (blue circles) and of coesite-bearing frothy inclusions (orange circles) is plotted versus the diameter of the sphere with equivalent volume; note that the froth vesicles and free vesicles are distinguished based on their different trends and that the division between the two trends (blue dashed lines) is drawn by eye (a). Vesicle size distribution (VSD) frequency histogram ( $\mathrm{x}$ axis in logarithmic scale) (b) and cumulative plot indicating the vesicle number density (VND) of each vesicle size class (c).

than the $R E V$ size, yield much higher $V N D$ values and appear thus more representative of the actual density of vesicles in MN tektite (Table 1). In spite of the shift towards lower median values at increasing voxel resolution, all VSD curves exhibit comparable positive-skews, indicating a non-linear increase in abundance of vesicles with decreasing vesicle size. In the cumulative $V S D$, the sharp increase of the smaller vesicles translates into a deviation from the exponential relation towards a power law (Fig. 4c).

The 3D characterization of the coesite-bearing frothy inclusions further confirms the main features observed in $2 \mathrm{D}$, that are: (i) the range of inclusion size of $200-600 \mu \mathrm{m}$ (length of the major axis) and elongation nearly parallel to the tektite layering (Fig. 3c; Fig. S4), (ii) the presence of a (up to) $120 \mu \mathrm{m}$ thick froth layer enclosing iii) a core composed by a mixture of silica phases (Fig. 1c,f). The presence of a core in most of the inclusions is confirmed by the $2 \mathrm{D}$ slices across the inclusions, where the denser $\mathrm{SiO}_{2}$ phases (quartz and coesite) appear as 

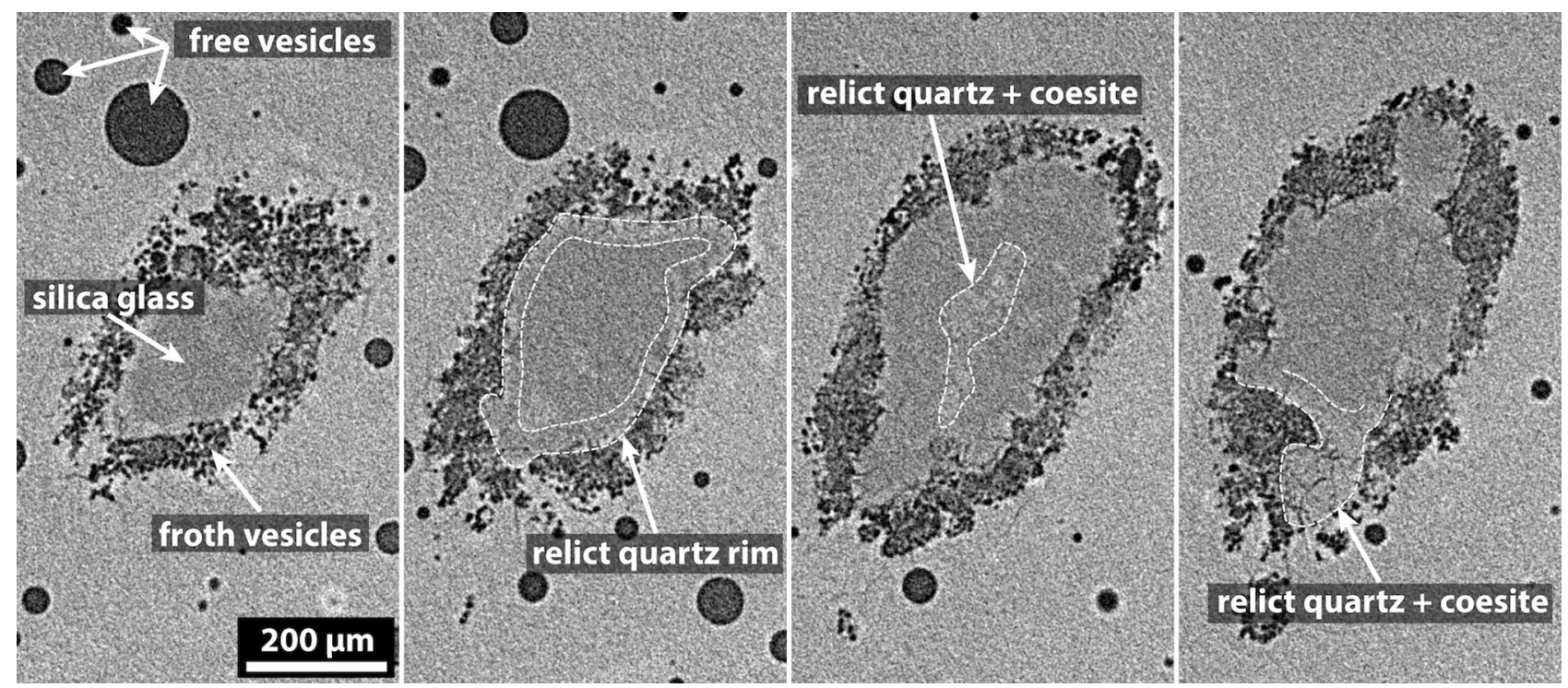

Figure 5. Sequence of $2 \mathrm{D}$ slices of a coesite-bearing frothy inclusion in MP26a obtained using XRM data reconstructed with an isotropic voxel size of $0.998 \mu \mathrm{m}$. The spatial distribution of vesicles, silica glass, relict quartz and coesite is inferred based on the phase contrast and indicated by the dashed lines.

bright spots arranged in patches or, in the case of the relict quartz rim, as a bright edge separating the inclusion core from the froth (Fig. 5). Overall, the inclusion cores have a darker appearance compared to the tektite glass, testifying to a lower bulk density of the mixture of the $\mathrm{SiO}_{2}$ phases compared to the rest of the tektite. The frothy inclusions constitute about $0.5 \mathrm{vol} \%$ of MP26, with a number density of $9.8 \mathrm{~mm}^{-3}$ in a volume of $20.36 \mathrm{~mm}^{3}$ (Table 1). In this specific volume, the number of inclusions per area measured in the $2 \mathrm{D}$ slices ranges from 1 to $3 \mathrm{~mm}^{-2}$, that is roughly one order of magnitude higher than the value of $0.14 \mathrm{~mm}^{-2}$ estimated by Glass et al. ${ }^{10}$. This difference could be explained by the fact that the analysis of the frothy inclusion would require a much larger $R E V$ (given their low number density compared to the free vesicles) and that not all the identified frothy inclusions are actually coesite-bearing or contain a core.

\section{Discussion}

Impact origin of MN tektite. In the lack of a confirmed impact site, the presence of shocked quartz, coesite and former reidite in $\mathrm{MN}$ tektites has been the main evidence for the impact cratering origin ${ }^{20,23,28}$, in contrast with the airburst hypothesis ${ }^{29}$. The new textural and chemical analyses of MP26 are basically consistent with previous work indicating an impact origin of the $\mathrm{MN}$ tektite ${ }^{10}$ and point to a porous target material, most probably a fine-grained quartz-rich sedimentary deposit ${ }^{20,30}$, able to preserve the observed short scale (15-20 $\mu \mathrm{m})$ compositional layering (Fig. S1).

Volatiles in MN tektite. One of the main questions on the formation of MN tektites is related to the origin and composition of the gas phase responsible for the vesiculation of the tektite melt. Vesicles in $\mathrm{MN}$ tektites are composed dominantly by $\mathrm{CO}_{2}$, with minor amounts of $\mathrm{O}_{2}, \mathrm{CO}$ and noble gases ${ }^{31}$, whilst, surprisingly, no measurable amount of $\mathrm{H}_{2} \mathrm{O}$ has ever been reported ${ }^{32}$. Compared to other tektites from the Australasian strewn field, MN tektites are characterized by a higher gas pressure in the vesicles (up to $1 / 3$ of atmospheric pressure ${ }^{33}$ ) and a noble gas composition enriched in $\mathrm{Ne}$ and $\mathrm{Ar}^{34}$. The gas pressure of the vesicles and the noble gas composition are normally used to estimate the height to which tektites were ejected by the impact before their quench in $\operatorname{air}^{35,36}$. However, given the atmospheric origin of noble gases, the formation of the vesicles in the tektite must be attributed to volatile species derived from the target rock.

If we assume that the lithology was a near-surface fine-grained quartz-rich sediment, it is highly unlikely that minor gas species other than $\mathrm{H}_{2} \mathrm{O}$ were present in sufficient concentration to explain the extensive vesiculation in the tektite melt, yielding to the high $V N D\left(>10^{3} \mathrm{~mm}^{3}\right)$ and low porosity (4.7-4.9 vol.\%; Table 1). Reasonably, $\mathrm{H}_{2} \mathrm{O}$ must have constituted the most abundant volatile component in the target rock and have nearly completely evaporated during the impact. The exceptionally low concentration of $\mathrm{H}_{2} \mathrm{O}$ in all tektites is indeed one of the main arguments for the impact origin and could be explained through a mechanism of dissociation of the $\mathrm{H}_{2} \mathrm{O}$ molecules into their atomic components ${ }^{37}$. The $\mathrm{H}_{2} \mathrm{O}$ dissociation into $\mathrm{H}_{2}+1 / 2 \mathrm{O}_{2}$ requires a very high energy and, in experimental systems, it is generally obtained from a vapour phase at high temperatures $\left(>>1000^{\circ} \mathrm{C}\right)$ produced by electric discharge ${ }^{38}$. For comparison with tektites, atomic bomb glasses that form under energetically comparable conditions yield comparable $\mathrm{H}_{2} \mathrm{O}$ concentration in the order of a few $\mathrm{ppm}^{39}$. Hence, assuming that a high amount of energy was available during the shock, the extensive vesiculation of MP26 can be reasonably interpreted as caused by the dissociation of the $\mathrm{H}_{2} \mathrm{O}$ molecules and rapid exsolution of their atomic components (mostly $\mathrm{H}_{2}$ ). In this regard, it is worth noting that the solubility of $\mathrm{H}_{2}$ in silicate melts can be orders of magnitude lower than that of $\mathrm{H}_{2} \mathrm{O}^{40,41}$, which points to a high initial supersaturation and to a consequently high nucleation. 
Such a mechanism of vesiculation could thus explain the presence of $\mathrm{H}_{2}$ as minor volatile component in a large number of tektites worldwide ${ }^{32}$.

Based on these considerations, as alternative to the atmospheric re-equilibration of the gas pressure in the vesicles during the ejection of the tektite ${ }^{35}$, the low pressure of the gas phase in the vesicles of MN tektite could be possibly explained by two concurring mechanisms: (i) bonding of $\mathrm{H}_{2}$ and $\mathrm{O}_{2}$ and further adsorption of $\mathrm{H}_{2} \mathrm{O}$ in the tektite glass and (ii) isochoric quench of the vesicle and eventual drop of the internal gas pressure (resulting from the gas equation of state). In this latter case, assuming an ideal behaviour of the gas phase contained in the vesicles and no exchange of mass from-toward the vesicle, the gas pressure is expected to drop to values of $10^{-2}-10^{-3}$ bar, that are consistent with the pressure values typically measured in tektite vesicles ${ }^{32}$.

Vesiculation mechanisms in the tektite melt. The presence of low-density gas vesicles in tektites suggests that the exsolution of the volatile phases initiated shortly after the shock-induced melting and terminated upon complete pressure release, before the quench of the tektite melt. Vesicle nucleation occurred both homogeneously in the tektite melt (free vesicles) and heterogeneously on the surface of relict quartz crystals (froth vesicles; Fig. 1f). The substantial difference between the two mechanisms is the supersaturation pressure $(\Delta P)$ required to initiate nucleation, that is largely reduced in the case of the heterogeneous nucleation ${ }^{42}$. The supersaturation pressure is expressed as the difference between the theoretical pressure of saturation of a volatile species dissolved in the melt and the actual pressure at which the volatile phase is exsolved. The value of $\Delta P$ generally increases with the increasing polymerization of the silicate melt and decreases with the increasing temperature ${ }^{43}$. In the case of MP26, the contrasting effect to nucleation due to the highly-polymerized nature of the tektite melt $\left(\mathrm{SiO}_{2}\right.$-rich composition; Table $\left.\mathrm{S} 1\right)$ was necessarily counterbalanced by the very high temperature and the consequent reduction of surface tension.

Although it is not possible to estimate the initial condition of supersaturation (the $\mathrm{H}_{2} \mathrm{O}+\mathrm{CO}_{2}$ content in the target material is unknown), a progressive increase of the $\Delta P$ value during the decompression stage can be inferred from the analysis of the VSD curves (Fig. 4b,c). Any departure from a near-equilibrium degassing trend is normally expressed by non-symmetric VSD and by a deviation from the exponential law in the cumulative $V S D^{44,45}$. Indeed, in the case of MP26, positive skews are observed in all the VSDs and the cumulative VSDs deviate from exponential to power law, suggesting an increase of the nucleation rate over time that is consistent with a non-linear pressure decrease during the post-shock decompression. At these conditions, the rapid increase of $\triangle P$ would rather favour the nucleation of new vesicles than the diffusive growth of the existing ones, limiting the possibility for them to coalesce ${ }^{46}$. This is evident in large adjacent free vesicles that underwent significant deformation without disruption of the melt septa (red circles in Fig. 3b) and in the densely-packed froth vesicles surrounding the coesite-bearing inclusions (Figs. $1 \mathrm{c}$ and $3 \mathrm{c}$ ).

In this frame of rapid decompression with increase of the $\Delta P$, the presence of the relict quartz rim surrounding the core of the inclusions was determinant for the formation of the froth layer (Fig. 1f). The surface of the relict quartz offered a preferential site for heterogeneous nucleation, by lowering the $\Delta P$ required to initiate nucleation. On these sites, nucleation occurred earlier compared to the rest of the tektite melt and unceasingly during the decompression (or possibly during pressure reverberations associated to the pore collapse ${ }^{2}$ ). A high and constant nucleation rate on the relict quartz surface was however necessary to sustain the formation of the densely-packed vesicle structure of the froth. This was possible because of the low wetting angle of quartz, allowing for a very fast detachment of yet small vesicles from the nucleation surface and consequent reactivation of the nucleation sites ${ }^{47}$. The process of reactivation of the nucleation site and generation of a froth structure has been observed experimentally in silicate melts at conditions of high volatile supersaturation. For example, through $\mu \mathrm{CT}$ in situ observation of $\mathrm{H}_{2} \mathrm{O}$ vesiculation experiments in crystal bearing silicate melts at high temperature, Pleše et al. ${ }^{48}$ described froth-like textures around silicate minerals, formed in response of a rapid decrease of the wetting angle. Analogue conditions were reproduced in carbonate assimilation experiments at high temperature by Blythe et al. ${ }^{49}$, who concluded that the rapid removal of $\mathrm{CO}_{2}$ vesicle from the nucleation site was responsible for the reactivation of the nucleation site. In both types of experiments, the coalescence of adjacent vesicles induced by their growth and expansion reduced the surface available for nucleation. In the case of MP26, the rather small $(5-50 \mu \mathrm{m})$ and homogeneous size of the froth vesicles indicates that coalescence was probably not efficient over the (very short) decompression time and that vesicle nucleation progressed unceasingly till the quench of froth structure. It must be noted, however, that few larger $(>50 \mu \mathrm{m})$ vesicles are sometimes observed in the outer froth layer of some coesite-bearing inclusions (Fig. 3c; Video SV2) and these may be the result of combined diffusive growth and coalescence mechanisms. We hypothesize that these vesicles are likely to be observed in inclusions presenting gaps in the relict quartz rim, thus lacking of surfaces for heterogeneous vesicle nucleation (see also Fig. 6a and further discussion below). A similar scenario may explain the lack of froth structures in lechatelierite particles and the typical occurrence of few larger vesicles, possibly resulting from the collapse of former froth vesicles following the complete melting of relict quartz (and the whole inclusion core) to form silica glass (Fig. 1g,h).

Time scale of vesiculation and tektite formation. We argued that all vesicles in MP26 formed very rapidly during the post-shock decompression and that their preservation was possible because of the subsequent quench of the tektite melt. Hence, the time scale of vesiculation $\left(\tau_{v e s}\right)$ must be comprised between the time of the shock melting $\left(t_{m}\right)$ and the time of the quench $\left(t_{q}\right)$ of the tektite melt $\left(\tau_{v e s} \leq t_{q}-t_{m}\right)$. In order to determine this time, we must consider that the tektite underwent shear deformation during the peak pressure and all free vesicles were subject to elongation, but only the smaller $(<50 \mu \mathrm{m})$ vesicles recovered to a fully spherical shape before the quench (Fig. 4b). The time necessary to recover the spherical shape is proportional to the size of the vesicle and the fact that the larger vesicles remained evidently ellipsoidal (e.g., very large vesicles in Fig. 3b) indicates 

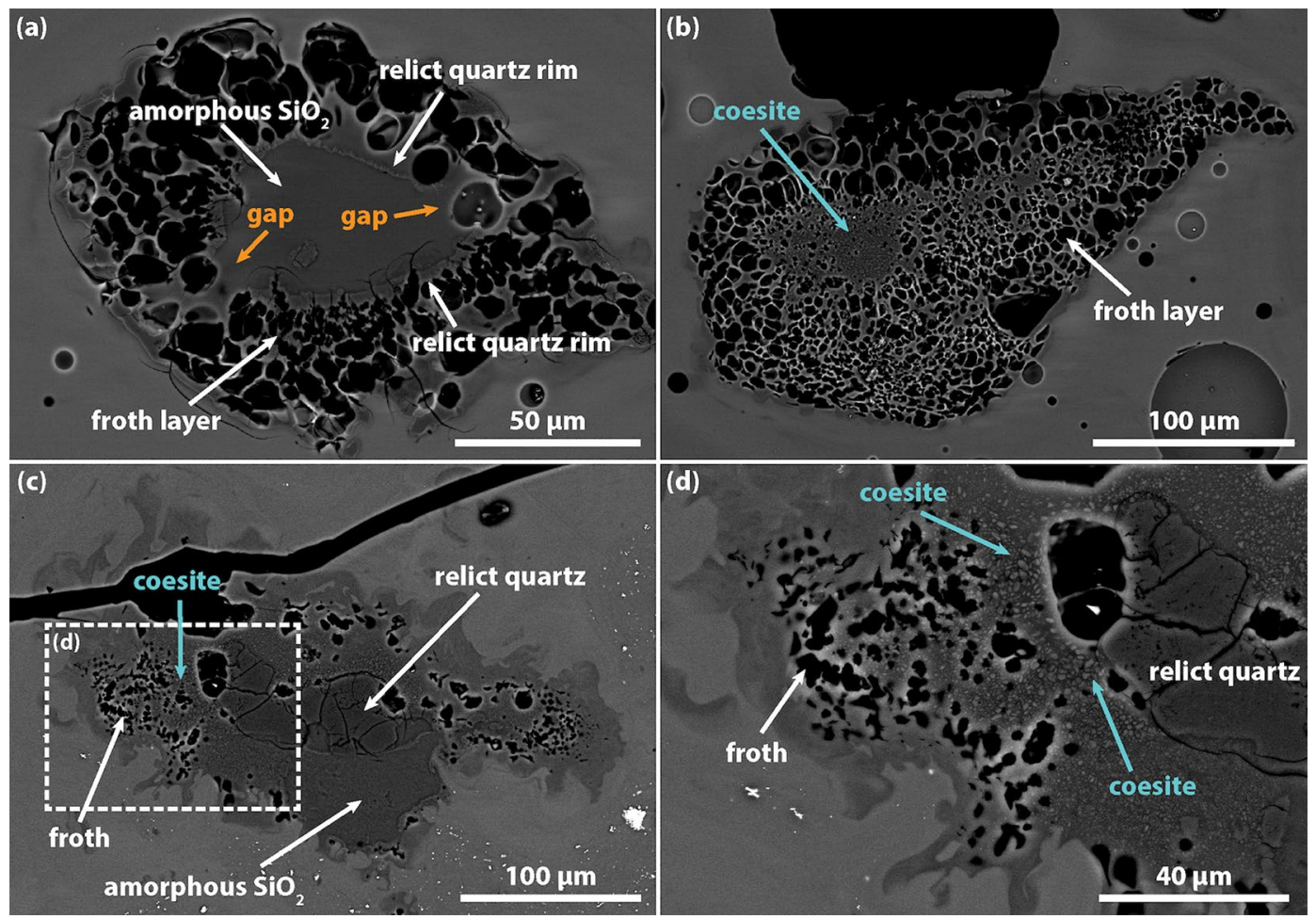

Figure 6. Backscattered electron images of coesite-bearing frothy inclusions from sample MN20 showing textural features comparable to MP26 (a,b). Note the presence of gaps in the relict quartz rim (a) and the outward increasing size of the vesicle constituting the froth layer. Coesite-bearing frothy inclusions from an impact glass of Pantasma crater (sample P20-3), Nicaragua, showing textural features similar to those described for coesite-bearing frothy inclusions of $\mathrm{MN}$ tektites $(\mathbf{c}, \mathbf{d})$.

that the time scale of vesiculation was comparable, or slightly shorter, than the time scale of vesicle relaxation $\left(\tau_{r e l}\right)$. Therefore, if we assume that shock decompression was nearly instantaneous and that a transient deformation of the vesicles occurred during the ejection of the tektite, we can reasonably compare the vesiculation time scale $\left(\tau_{\text {ves }}\right)$ with the vesicle relaxation time scale $\left(\tau_{\text {rel }}\right)$, expressed by the equation ${ }^{50}$ :

$$
\tau_{v e s} \approx \tau_{r e l}=\frac{R \eta}{\sigma}
$$

where $R$ is the equivalent sphere diameter of the vesicle, $\eta$ is the viscosity and $\sigma$ is the surface tension of the tektite melt. It follows that, by assigning to the tektite melt an average viscosity of $\sim 10^{4} \mathrm{~Pa} \mathrm{~s}$ (calculated at $1 \mathrm{~atm}$ and $1400{ }^{\circ} \mathrm{C}$ using the viscosity model of Giordano et al..$^{51}$ ) and a surface tension of $0.36 \mathrm{~N} / \mathrm{m}$ (measured in a natural rhyolite at $1388^{\circ} \mathrm{C}^{52}$ ) a characteristic relaxation time of $2.8 \mathrm{~s}$ is obtained for a vesicle of $100 \mu \mathrm{m}$ diameter. The vesicle relaxation time scale increases proportionally with the vesicle size and, considering that the sphericity of the free vesicles decreases with their increasing size (Fig. 4a), it is possible to constrain the time scale for the formation of MN tektite in the order of seconds. This is in accordance with the maximum quench time of $10 \mathrm{~s}$ proposed by Walter ${ }^{9}$, that is required to prevent the full transformation of coesite into cristobalite at high temperature.

If the same consideration is applied to the vesicles constituting the froth layer of coesite-bearing inclusions, the generally smaller size and sphericity of the froth vesicles compared to free vesicles (Fig. 4b) testifies to a shorter time for the formation and quench of the froth structure, compared to what is inferred for the tektite melt. Hence, by considering an average size $(R)$ of $10 \mu \mathrm{m}$ for the highly deformed froth vesicles, the time scale for the formation of the froth layer could be estimated to be less than $1 \mathrm{~s}$. This comparison suggests that coesite-bearing inclusions may have experienced a much more rapid quench compared to the tektite melt, likely due to energy dissipation during the froth expansion. This would represent a reasonable explanation of how the coesite-bearing frothy inclusions were preserved in the tektite melt.

Coesite survival in impact melt rocks. The MN tektite sample MP26 lacks petrographic features that could testify to pressure exceeding $10 \mathrm{GPa}$, such as planar deformation features (PDF) in quartz or stishovite. On the counterpart, peak temperatures in excess of $1700{ }^{\circ} \mathrm{C}$ (melting point of pure $\mathrm{SiO}_{2}$ ) are indicated by the presence of lechatelierite inclusions. Upon shock unloading, at any temperature above the liquidus temperature of the tektite $\left(\sim 1130^{\circ} \mathrm{C}\right.$; calculated at $0.1 \mathrm{GPa}$ using Rhyolite-MELTS code ${ }^{33}$; Table S1), the back transformation of coesite into a more stable form of $\mathrm{SiO}_{2}$ would be expected to occur, making the retrieval of coesite in MP26 quite surprising. Glass et al. ${ }^{10}$ argued that the froth layer surrounding the coesite-bearing inclusion was determinant 
for the survival of coesite within the core of the inclusions, but the physical processes responsible of the froth formation were not investigated in detail. The new 3D textural characterization demonstrated that the froth layer encloses effectively the coesite-bearing inclusions (Fig. 3c; Fig. S4) and allowed to formulate new hypotheses on the formation mechanisms and time scales of the froth structures in MP26. In this frame, the role of the froth on the survival of coesite was twofold. On one hand, it contributed to rapidly subtract heat from the inclusion core through the endothermic process of gas exsolution and expansion, while, on the other hand, it provided thermal insulation to the core from the surrounding hot tektite melt. The preservation of the coesite was indeed possible because the unstable vesicle packing condition of the froth was created in a very short time $(<1 \mathrm{~s})$ and maintained till the ultimate quench of the tektite melt to a glass (occurred in few seconds). These conditions did not occur for all the inclusions as, in some cases, the froth did not fully enclose the inclusion core or the froth vesicles coalesced and detached from the relict quartz surfaces. In these cases, the thermal insulation was not efficient and the inclusion underwent complete melting generating lechatelierite (Fig. 1g,h).

We show that the development of froth structures around mineral or lithic inclusions during the post-shock decompression was instrumental in preserving shock-produced coesite in a Muong Nong tektite. Note that the wide applicability of the present conclusion derived from detailed investigations on the Muang Phin tektite (sample MP26) is suggested by the observation of very similar coesite/quartz/froth relationships in another MN tektite specimen (sample MN20) collected $8 \mathrm{~km}$ North of Muong Nong village. The presence of small gaps in the relict quartz rim, corresponding to less vesiculated regions of the froth (Fig. 6a), as well as the increasing vesicle size outwards of the froth (Fig. 6b; Fig. S2a), confirm that the presence of surfaces for heterogeneous vesicle nucleation was fundamental for the development of the froth. This is further supported by the identification of coesite in frothy inclusions within an impact glass of Pantasma crater, Nicaragua ${ }^{54}$ (sample P20-3; Figs. 6c,d; Fig. S2b). Highly vesicular textures, froth and foam commonly occur in impact melt rocks, suevite and impact melt spherules from several impact structures, e.g., Barringer, Kamil, Bosumtwi, Ries, Rochechouart, Lonar, etc., and impact sites, e.g., Libyan Desert Glass field ${ }^{55}$. Decompression foamy structures may thus be important petrographic settings in which to search for key shock metamorphic mineral assemblages in impact melt rocks. This maybe particularly useful in addressing the nature of enigmatic natural glasses whose impact origin is still debated due to the lack of a high-pressure record like, for instance, the Dakhla and other similar glasses ${ }^{56-59}$.

\section{Tektite samples}

The MN tektite sample MP26 is the same sample as that investigated by Glass et al. ${ }^{10}$, collected in the general area of Muang Phin, Laos ( $16^{\circ} 32^{\prime}$ N Lat, $106^{\circ} 01^{\prime}$ E Long) as reported by Schnetzler and McHone ${ }^{60}$. Two polished thin sections of MP26 were prepared for mineralogical and petrographic investigation by optical microscopy, Fourier transformed infrared spectroscopy (FTIR), and field emission gun-scanning electron microscopy (FEG-SEM). Three cylindrical cores with diameter of $\sim 10 \mathrm{~mm}$ (MP26a), $\sim 5 \mathrm{~mm}$ (MP26b) and $\sim 3 \mathrm{~mm}$ (MP26c) and a height of $10 \mathrm{~mm}$ were obtained from a bulk piece of MP26 and analysed by a multiscale approach employing the X-ray Computed micro-Tomography technique with different experimental setups (Table 1). In particular, samples were imaged using a commercial 3D X-ray microscope system (XRM, MP26a), a custom-developed microfocus $\mathrm{X}$-ray CT station (MCT, MP26a) and a synchrotron radiation-based set up (SR- $\mu$ CT, MP26b and MP26c).

The second MN tektite briefly presented here (MN20) was collected by two of us (PR and SS) in January 2019 within a gravel quarry $8 \mathrm{~km}$ North of Muong Nong village ( $16^{\circ} 26.543^{\prime} \mathrm{N}$ Lat, $106^{\circ} 28.825^{\prime} \mathrm{E}$ Long). One lighter colored fragment with white inclusions and abundant vesicles similar to MP26 was selected among a total of $320 \mathrm{~g}$ of fragments, mounted in an epoxy disk and polished for FEG-SEM and Raman analyses (Fig. S2). Finally, a 1.3 g glass fragment (P20-3) was collected by two of us (PR and EN) in March 2020 within the Pantasma crater depression ( $13^{\circ} 24.015^{\prime} \mathrm{N}$ Lat, $85^{\circ} 55.241^{\prime} \mathrm{W}$ Long) was also mounted in an epoxy disk and polished for FEGSEM and Raman analyses (Fig. S2).

Analytical methods. Chemical analyses of major elements were carried out at the Centro per l'Integrazione della Strumentazione Scientifica (CISUP)_Università di Pisa (Italy), using a FEI Quanta 450 Field Emission Scanning Electron Microscope equipped with an EDX spectrometer Bruker QUANTAX XFlash Detector 6|10 (analyses reported in the supplementary material). FTIR spectra were acquired on a thin slab of MP26 double polished at a thickness of $285 \mu \mathrm{m}$. Several spectra were collected along a transect across the sample with a step size of $150 \mu \mathrm{m}$, a large spot size $\left(250 \times 250 \mu \mathrm{m}^{2}\right)$ was adopted in order to improve $\mathrm{S} / \mathrm{N}$ ratio and average the effect of bubbles. FTIR spectra were acquired using a Bruker Hyperion 3000 microscope equipped with a $\mathrm{KBr}$ broadband beam splitter, a $15 \mathrm{X}$ objective and a liquid nitrogen cooled mercury cadmium telluride detector at Laboratori Nazionali di Frascati-Istituto Nazionale di Fisica Nucleare (LNF-INFN, Frascati, Rome, Italy). The nominal resolution was set at $4 \mathrm{~cm}^{-1}$, and 64 scans were averaged for both spectrum and background.

Lab-based CT measurements. The 3D characterization of the bulk tektite sample and of the coesitebearing frothy inclusions was performed by high-resolution X-ray computed tomography (CT) using three different set ups. Sample MP26a has been analysed with the TomoLab station ${ }^{61,62}$, a X-ray microtomographic (MCT) system custom-developed at the Elettra synchrotron laboratory in Basovizza (Trieste, Italy) and based on a microfocus source (Hamamatsu, L9181, minimum focal spot size $=5 \mu \mathrm{m}$ ) allowing to work in a voltage range of $40-130 \mathrm{kV}$ with a maximum power of $39 \mathrm{~W}$. A water-cooled, 12-bit CCD camera (Photonic Science, VHR) has been used as detector. This camera has a $4008 \times 2672$ pixels full frame imager coupled by a fiber-optic tape to a gadolinium oxysulphide scintillator and an effective pixel size of $12.5 \mu \mathrm{m} \times 12.5 \mu \mathrm{m}$ yielding a maximum field of view (FOV) of about $50 \mathrm{~mm} \times 33 \mathrm{~mm}$. The experimental parameters used for the tomographic scans are reported in Table S2. The tomographic reconstruction was performed using the commercial software COBRA 7 (Exxim, 
USA) based on the Feldkamp algorithm ${ }^{63}$. Volume visualization with volume rendering procedures (Fig. 3a) was performed by means of the commercial software VGStudio MAX 2.0 (Volume Graphics, Germany).

The same sample MP26a has been measured by using a Zeiss Xradia 620 Versa X-ray Microscope (XRM), adopting voxel resolutions of $12.48 \mu \mathrm{m}, 4.24 \mu \mathrm{m}, 1.092 \mu \mathrm{m}$ and $0.998 \mu \mathrm{m}$. This instrument can operate in a voltage range of $30-160 \mathrm{kV}$ with a maximum power of $25 \mathrm{~W}$. The two stages magnification using scintillators screens coupled to a high-resolution microscope camera $(2048 \times 2048$ pixels $)$ allow Scout-and-Zoom workflows, where features and regions of interest can be identified during a short coarse resolution scan. Then, it is possible to zoom in by selecting a higher magnification objective to visualize structure at high resolution in the sample volume with a non-destructive method. For the current study, two overview scans with voxel sizes of $12.48 \mu \mathrm{m}$ and $4.25 \mu \mathrm{m}$ were performed before performing high-resolution scans at the microscale. The experimental conditions adopted for the different scans are reported in Table S2. The tomographic reconstruction was performed using the software integrated in the XRM instrument.

Synchrotron radiation-based CT measurements. Samples M26b and MP26c have been measured by synchrotron radiation X-ray microtomography $(\mathrm{SR}-\mu \mathrm{CT})$ at the SYRMEP beamline of Elettra ${ }^{64,65}$ using a filtered polychromatic X-ray beam (filters $=1.5 \mathrm{~mm} \mathrm{Si}+1 \mathrm{~mm} \mathrm{Al}$ ). The detector consisted of a 16-bit, water-cooled, sCMOS macroscope camera (Hamamatsu C11440-22C) with a $2048 \times 2048$ pixels chip coupled through a high numerical aperture optics to a $17 \mu \mathrm{m}$-thick GGG:Eu scintillator screen. For sample MP26b the effective pixel size of the camera was set at $2.5 \mu \mathrm{m}(\mathrm{FOV} \sim 5.1 \mathrm{~mm} \times 4.0 \mathrm{~mm})$ while it was set at $0.9 \mu \mathrm{m}(\mathrm{FOV} \sim 1.8 \mathrm{~mm} \times 1.8 \mathrm{~mm})$ for sample MP26c. Scans were acquired in propagation-based phase-contrast mode ${ }^{66}$ setting a sample-to-detector distance of $150 \mathrm{~mm}$. For each sample 900 (pixel size $=2.5 \mu \mathrm{m}$ ) or 1800 projections (pixel size $=0.9 \mu \mathrm{m}$ ) were acquired over a total scan angle of $180^{\circ}$ and with an exposure time/projection of $2.5 \mathrm{~s}$. For cores having a maximum height exceeding the vertical FOV of the camera, scans were acquired at different positions along the vertical axis then stitching the reconstructed volumes. Scans at $0.9 \mu \mathrm{m}$ of pixel size were acquired in local area mode zooming in regions of interest of the sample. Volume visualization with volume rendering procedures (Fig. 3b,c) was performed by means of the free software Fiji ${ }^{67}$ using the 3D Viewer plugin.

Received: 5 August 2020; Accepted: 30 October 2020

Published online: 26 November 2020

\section{References}

1. French, B. M. \& Koeberl, C. The convincing identification of terrestrial meteorite impact structures: What works, what doesn't, and why. Earth Sci. Rev. 98, 123-170 (2010).

2. Folco, L., Mugnaioli, E., Gemelli, M., Masotta, M. \& Campanale, F. Direct quartz-coesite transformation in shocked sandstone from Kamil Crater (Egypt). Geology 46, 739-742 (2018).

3. Langenhorst, F. Nanostructures in ultrahigh-pressure metamorphic coesite and diamond: A genetic fingerprint. Mitt. Österr. Mineral. Ges. 148, 401-412 (2003).

4. Chen, M., Xiao, W. \& Xie, X. Coesite and quartz characteristic of crystallization from shock-produced silica melt in the Xiuyan crater. Earth Planet. Sci. Lett. 297, 306-314 (2010).

5. Fazio, A., Mansfeld, U. \& Langenhorst, F. Coesite in suevite from the Ries impact structure (Germany): From formation to postshock evolution: Meteorit. Planet. Sci. 52, 1437-1448 (2017).

6. Stähle, V., Altherr, R., Koch, M. \& Nasdala, L. Shock induced growth and metastability of stishovite and coesite in lithic clasts from suevite of the Ries impact crater (Germany). Contrib. Mineral. Petrol. 155, 457-472 (2008).

7. Campanale, F. et al. Evidence for subsolidus quartz-coesite transformation in impact ejecta from the Australasian tektite strewn field. Geochim. Cosmochim. Acta 264, 105-117 (2019).

8. Mosenfelder, J. L. \& Bohlen, S. R. Kinetics of the coesite to quartz transformation. Earth Planet. Sci. Lett. 153, 133-147 (1997).

9. Walter, L. S. Coesite discovered in tektites. Science 147, 1029-1032 (1965).

10. Glass, B. P., Folco, L., Masotta, M. \& Campanale, F. Coesite in a Muong Nong-type tektite from Muong Phin, Laos: Description, formation, and survival. Meteorit. Planet. Sci. 55, 253-273 (2020).

11. Glass, B. P. \& Wu, J. Coesite and shocked quartz discovered in the Australasian and North American microtektite layers. Geology 21, 435-438 (1993).

12. Amare, K. \& Koeberl, C. Variation of chemical composition in Australasian tektites from different localities in Vietnam. Meteorit. Planet. Sci. 41, 107-123 (2006).

13. Beran, A. \& Koeberl, C. Water in tektites and impact glasses by Fourier-transformed infrared spectrometry. Meteorit. Planet. Sci. 32, 211-216 (1997).

14. Watt, N., Bouchet, R. A. \& Lee, C.-T.A. Exploration of tektite formation processes through water and metal content measurements. Meteorit. Planet. Sci. 46, 1025-1032 (2011).

15. Folco, L. et al. Transantarctic Mountain microtektites: Geochemical affinity with Australasian microtektites. Geochim. Cosmochim. Acta 73, 3694-3722 (2009).

16. Ma, P. et al. Beryllium-10 in Australasian tektites: Constraints on the location of the source crater. Geochim. Cosmochim. Acta 68, 3883-3896 (2004).

17. Rochette, P. et al. ${ }^{10} \mathrm{Be}$ in Australasian microtektites compared to tektites: Size and geographic controls. Geology 46, 803-806 (2018).

18. Koeberl, C. Geochemistry and origin of Muong Nong-type tektites. Geochim. Cosmochim. Acta 56, 1033-1064 (1992).

19. Glass, B. P. \& Pizzuto, J. E. Geographic variation in Australasian microtektite concentrations: Implications concerning the location and size of the source crater. J. Geophys. Res. 99, 19075-19082 (1994).

20. Glass, B. P. \& Koeberl, C. Australasian microtektites associated with impact ejecta in the South China Sea and the Middle Pleistocene supereruption of Toba. Meteorit. Planet. Sci. 41, 305-326 (2006).

21. Prasad, M. S., Mahale, V. P. \& Kodagali, V. N. New sites of Australasian microtektites in the central Indian Ocean: Implications for the location and size of source crater. J. Geophys. Res. 112, 1-11 (2007).

22. Folco, L., Glass, B. P., D’Orazio, M. \& Rochette, P. A common volatilization trend in transantarctic mountain and Australasian microtektites: Implications for their formation model and parent crater location. Earth Planet. Sci. Lett. 293, 135-139 (2010).

23. Folco, L. et al. Shocked quartz and other mineral inclusions in Australasian microtektites. Geology 38, 211-214 (2010). 
24. Folco, L., Glass, B. P., D’Orazio, M. \& Rochette, P. Impactor identification in Australasian microtektites based on Cr, Co and $\mathrm{Ni}$ ratios. Geochim. Cosmochim. Acta 222, 550-568 (2018).

25. Sieh, K. et al. Australasian impact crater buried under the Bolaven volcanic field, Southern Laos. Proc. Natl. Acad. Sci. 117, 1346-1353 (2019).

26. Žák, K., Skála, R., Pack, A., Ackerman, L. \& Krížová, Š. Triple oxygen isotope composition of Australasian tektites. Meteorit. Planet. Sci. 54, 1167-1181 (2019).

27. Krí̌ová, Š, Skála, R., Halodová, P., Žák, K. \& Ackerman, L. Near end-member shenzhuangite, $\mathrm{NiFeS}_{2}$, found in Muong Nong-type tektites from Laos. Am. Mineral. 104, 1165-1172 (2019).

28. Cavosie, A. J., Timms, N. E., Erickson, T. M. \& Koeberl, C. New clues from Earth's most elusive impact crater: Evidence of reidite in Australasian tektites from Thailand. Geology 46, 203-206 (2018).

29. Wasson, J. T. Layered tektites: A multiple impact origin for the Australasian tektites. Earth Planet. Sci. Lett. 102, 95-109 (1991).

30. Mizera, J., Randa, Z. \& Kameník, J. On a possible parent crater for Australasian tektites: Geochemical, isotopic, geographical and other constraints. Earth Sci. Rev. 154, 123-137 (2016).

31. Jessberger, E. \& Gentner, W. Mass spectrometric analysis of gas inclusions in Muong Nong glass and Libyan Desert glass. Earth Planet. Sci. Lett. 14, 221-225 (1972).

32. Žák, K., Skála, R., Randa, Z. \& Mizera, J. A review of volatile compounds in tektites, and carbon content and isotopic composition of moldavite glass. Meteorit. Planet. Sci. 47(6), 1010-1028 (2012).

33. Koeberl, C. Geochemistry of Muong Nong type tektites: A review. In Second International Conference on Natural Glasses (Prague 1987) (ed. Konta, J.) 371-377 (Charles University, Prague, 1988).

34. Mizote, S., Matsumoto, T., Matsuda, J. \& Koeberl, C. Noble gases of Muong Nong-type tektites: Their implication. Meteorit. Planet. Sci. 38, 747-758 (2003).

35. Matsuda, J., Matsubara, K. \& Koeberl, C. Origin of tektites: Constraints from heavy noble gas concentrations. Meteoritics 28, 586-589 (1993).

36. Pinti, D. L., Matsumoto, T., Matsuda, J. \& Fang, Z. Distribution of noble gases in Chinese tektites: Implication for neon solubility in natural glasses. Meteorit. Planet. Sci. 39, 87-96 (2004).

37. Vickery, A. M. \& Browning, L. Water depletion in tektites. Meteoritics 26, 403 (1991).

38. Oldenberg, O. The Energy of Dissociation $\mathrm{H}_{2} \mathrm{O} \mathrm{H}+\mathrm{OH}$. J. Chem. Phys. 17, 1059 (1949).

39. Glass, B.P., Senrze, F.E., Muenow, D.W., Aggrey, K.E. \& Thorpe A. Atomic bomb glass beads: Tektite and microtektite analogs. in Proceedings of the 2nd International Conference on Natural Glasses (ed. J. Konta), 361-369 (1988).

40. Carroll, M. R. \& Stolper, E. M. Noble-gas solubilities in silicate melts and glasses-New experimental results for argon and the relationship between solubility and ionic porosity. Geochim. Cosmochim. Acta 57, 5039-5051 (1993).

41. Hirschmann, M. M., Withers, A. C., Ardia, P. \& Foley, N. T. Solubility of molecular hydrogen in silicate melts and consequences for volatile evolution of terrestrial planets. Earth Planet. Sci. Lett. 345-348, 38-48 (2012).

42. Hurwitz, S. \& Navon, O. Bubble nucleation in rhyolitic melts: Experiments at high pressure, temperature, and water content. Earth Planet. Sci. Lett. 122, 267-280 (1994).

43. Mourtada-Bonnefoi, C. C. \& Laporte, D. Kinetics of bubble nucleation in a rhyolitic melt: An experimental study of the effect of ascent rate. Earth Planet. Sci. Lett. 218, 521-537 (2004).

44. Bai, L., Baker, D. R. \& Rivers, M. Experimental study of bubble growth in Stromboli basalt melts at 1 atm. Earth Planet. Sci. Lett. 267, 533-547 (2008).

45. Masotta, M., Ni, H. \& Keppler, H. In situ observations of bubble growth in basaltic, andesitic and rhyodacitic melts. Contrib. Mineral. Petrol. 167, 967 (2014).

46. Masotta, M. \& Keppler, H. A new hydrothermal moissanite cell apparatus for optical in-situ observations at high pressure and high temperature, with applications to bubble nucleation in silicate melts. Am. Mineral. 102, 2022-2031 (2017).

47. Laporte, D. Wetting behavior of partial melts during crustal anatexis: The distribution of hydrous silicic melts in polycrystalline aggregates of quartz. Contrib. Mineral. Petrol. 116, 486-499 (1994).

48. Pleše, P. et al. Dynamic observations of vesiculation reveal the role of silicate crystals in bubble nucleation and growth in andesitic magmas. Lithos 296, 532-546 (2018).

49. Blythe, L. S. et al. $\mathrm{CO}_{2}$ bubble generation and migration during magma-carbonate interaction. Contrib. Mineral. Petrol. 169, 42 (2015).

50. Rust, A. C., Manga, M. \& Cashman, K. V. Determining flow type, shear rate and shear stress in magmas from bubble shapes and orientations. J. Volcanol. Geotherm. Res. 122, 111-132 (2003).

51. Giordano, D., Russell, J. K. \& Dingweel, D. B. Viscosity of magmatic liquids: A model. Earth Planet. Sci. Lett. 271(617), 123-134 (2008).

52. Bagdassarov, N., Dorfman, A. \& Dingwell, D. B. Effect of alkalis, phosphorus, and water on the surface tension of haplogranite melt. Am. Mineral. 85, 33-40 (2000).

53. Gualda, G. A. R., Ghiorso, M. S., Lemons, R. V. \& Carley, T. L. Rhyolite-MELTS: A modified calibration of MELTS optimized for silica-rich, fluid-bearing magmatic systems. J. Petrol. 53, 875-890 (2012).

54. Rochette, P. et al. Pantasma: A Pleistocene circa 14 km diameter impact crater in Nicaragua. Meteorit. Planet. Sci. 4, 880-901 (2019).

55. Osinski, G.R., Grieve, R.A.F., Marion, C. \& Chanou, A. Impact melting. in Impact Cratering - Processes and Products (eds. Osinski G.R. and Pierazzo E.) (Wiley-Blackwell, Oxford, 2013).

56. Osinski, G. R. et al. Evidence for a 200-100 ka meteorite impact in the Western Desert of Egypt. Earth Planet. Sci. Lett. 253, 378-388 (2007).

57. Osinski, G. R. et al. The Dakhleh Glass: Product of an airburst or cratering event in the Western Desert of Egypt?. Meteorit. Planet. Sci. 43, 2089-2107 (2008).

58. Roperch, P. et al. Surface vitrification caused by natural fires in Late Pleistocene wetlands of the Atacama Desert. Earth Planet. Sci. Lett. 469, 15-26 (2017).

59. Folco, L. et al. (eds) The Geology of Egypt. Regional Geology Reviews (Springer, Cham, 2020).

60. Schnetzler, C. C. \& McHone, J. F. Source of the Australasian tektites: Investigating possible sites in Laos. Meteor. Planet. Sci. 31, 73-76 (1996).

61. Polacci, M., Baker, D. R., Mancini, L., Favretto, S. \& Hill, E. J. Vesiculation in magmas from Stromboli and implications for normal Strombolian activity and paroxysmal explosions in basaltic systems. J. Geophys. Res. Solid Earth 114, B01206 (2009).

62. Zandomeneghi, D. et al. Quantitative analysis of X-ray microtomography images of geomaterials: Application to volcanic rocks. Geosphere 6, 793-804 (2010).

63. Feldkamp, L. A., Davis, L. C. \& Kress, J. W. Practical cone-beam algorithm. J. Opt. Soc. Am. A. 1, 612-619 (1984).

64. Tromba, G. et al. The SYRMEP beamline of Elettra: Clinical mammography and bio-medical applications. AIP Conf. Proc. 1266, 18-23 (2010).

65. Baker, D. R. et al. An introduction to the application of $\mathrm{x}$-ray microtomography to the three-dimensional study of igneous rocks. Lithos 148, 262-276 (2012).

66. Cloetens, P., Barrett, R., Baruchel, J., Guigay, J. P. \& Schlenker, M. Phase objects in synchrotron radiation hard X-ray imaging. J. Phys. D Appl. Phys. 29, 133-146 (1996).

67. Schindelin, J. et al. Fiji: An open-source platform for biological-image analysis. Nat. Methods 9, 676-682 (2012). 


\title{
Acknowledgements
}

This study was supported by the PRIN (2017J277S9) project "Time scales of solidification in magmas: Application to Volcanic Eruptions, Silicate Melts, Glasses, Glass-Ceramics" to MM. The authors are grateful to the Editor D. Pinti and to three anonymous reviewers for their valuable comments. We acknowledge Elettra Sincrotrone Trieste for providing access to its synchrotron radiation facilities and for financial support. We thank G. Lanzafame (University of Catania, Italy) for useful discussions and G. Montagnac (CNRS) who operated the Raman spectrometer at the ENS de Lyon. The national Raman facility in Lyon is supported by the Institut National des Sciences de l'Univers (INSU). Field works was supported in Laos by A*midex foundation from Aix-Marseille Université, and in Nicaragua by IGG-CIGEO.

\section{Author contributions}

M.M. and L.F. conceived the study. M.M., S.P., L.F., F.C., L.M. and N.G. collected the X-ray tomographic data. M.M., S.P., L.M. and N.G. elaborated the X-ray tomographic data. L.F. collected FEG-SEM data. F.R. collected and interpreted the FTIR data. M.M., S.P., L.F., B.G. and F.C. interpreted the results. M.M. and L.F. wrote the manuscript with inputs from the other authors. P.R., S.S. and E.N. provided the tektite samples MN20 and impact glass P20-3. All the authors agree with the results and conclusions.

\section{Competing interests}

The authors declare no competing interests.

\section{Additional information}

Supplementary information is available for this paper at https://doi.org/10.1038/s41598-020-76727-6.

Correspondence and requests for materials should be addressed to M.M.

Reprints and permissions information is available at www.nature.com/reprints.

Publisher's note Springer Nature remains neutral with regard to jurisdictional claims in published maps and institutional affiliations.

\begin{abstract}
Open Access This article is licensed under a Creative Commons Attribution 4.0 International License, which permits use, sharing, adaptation, distribution and reproduction in any medium or format, as long as you give appropriate credit to the original author(s) and the source, provide a link to the Creative Commons licence, and indicate if changes were made. The images or other third party material in this article are included in the article's Creative Commons licence, unless indicated otherwise in a credit line to the material. If material is not included in the article's Creative Commons licence and your intended use is not permitted by statutory regulation or exceeds the permitted use, you will need to obtain permission directly from the copyright holder. To view a copy of this licence, visit http://creativecommons.org/licenses/by/4.0/.
\end{abstract}

(C) The Author(s) 2020 